\title{
Olive tree irrigation as a climate change adaptation measure in Alentejo, Portugal
}

\author{
Helder Fraga ${ }^{\mathrm{a}, \mathrm{b}, *}$, Joaquim G. Pinto ${ }^{\mathrm{b}}$, João A. Santos ${ }^{\mathrm{a}}$ \\ ${ }^{\text {a }}$ Centre for the Research and Technology of Agro-Environmental and Biological Sciences (CITAB), Universidade de Trás-os-Montes e Alto Douro (UTAD), Vila Real, \\ Portugal \\ ${ }^{\mathrm{b}}$ Institute for Meteorology and Climate Research (IMK-TRO), Karlsruhe Institute of Technology (KIT), Karlsruhe, Germany
}

\section{A R T I C L E I N F O}

\section{Keywords:}

Olive trees

Crop modeling

Climate change

Irrigation

Olive yield

Portugal

\begin{abstract}
A B S T R A C T
Climate change projections for Southern Europe reveal warming and drying trends for the upcoming decades, bringing important challenges to Portuguese olive orchards in particular. We analyzed irrigation as an adaptation measure to ensure the future sustainability of olive tree yields in Alentejo, the main olive producing area in Portugal. A dynamic crop model was used to simulate olive tree yields over the baseline (1981-2005) and two future scenarios (RCP4.5 and RCP8.5, 2021-2080), using a 4 member-ensemble of state-of-the-art climate model chains. Climate change projections point to an increase in mean temperature (of up to $2{ }^{\circ} \mathrm{C}$ by 2080) and potential evapotranspiration $(40-50 \mathrm{~mm})$, while a decrease in precipitation $(-80$ to $-90 \mathrm{~mm})$ and actual evapotranspiration $(-50$ to $-70 \mathrm{~mm}$ ), under both future scenarios. Future yield decreases $15-20 \%$ (for RCP4.5 and RCP8.5) and accumulated losses can reach $-8 \mathrm{t} / \mathrm{ha}$ to $-10 \mathrm{t} / \mathrm{ha}$ by 2080 . This decrease is due to enhanced heat and water stress under future climate conditions. As an adaptation measure, irrigation was simulated, but only applied at a certain water stress level. The results indicate higher yields due to this adaptation strategy, in range with the present values ( $\pm 1 \%$ ), thus alleviating the projected yield decreases in the future. The amount of water required for irrigation ranges from 60 to $85 \mathrm{~mm}$, depending on the RCP, which corresponds to $0.6-1$ times the projected decrease in precipitation. However, this value can reach up to 2 times for one climate model chain. We conclude that while irrigation is a feasible adaptation measure against the threats of climate change in Alentejo olive orchards, this strategy may be threatened by the scarcity of water resources. Outlining appropriate, timely and cost-effective adaptation measures is critical for the sustainability of both the environment and the Alentejo olive sector.
\end{abstract}

\section{Introduction}

The olive tree (Olea europaea L.) is one of the most important crops in the Mediterranean basin, where it has been used under rainfed conditions in traditional systems characterized by low plantation density and low productivity since many centuries (Villaobos et al., 2006). Its growth and development is mainly controlled by atmospheric conditions (Moriondo et al., 2015; Orlandi et al., 2012; Vossen, 2007). In fact, air temperatures and water availability strongly influence crop development, which ultimately impact crop yields (Vossen, 2007). Many of the world's olive growing regions are located in areas with Mediterranean-type climates, which are characterized by demanding climatic conditions for plant growth. In Portugal, olive orchards are strongly exposed to thermal and hydric stresses during the growing season, more noticeable during summer and in the innermost areas of the country. As an example, the Alentejo region (Fig. 1a), which includes 3 sub-regions with "Protected Denomination of Origin" (DOP), is the main olive oil producing region in Portugal (Fig. 1b) (INE, 2019), and receives a total precipitation in the summer months (June-JulyAugust) of approximately $30 \mathrm{~mm}$.

Water availability is generally essential for crops, but particularly for achieving suitable yields (Iglesias and Garrote, 2015). Olives are a very drought tolerant species, with a lower limit for annual precipitation around $350 \mathrm{~mm}$ (Ponti et al., 2014). Nonetheless, water stress may result in a wide range of negative impacts (Arampatzis et al., 2018), such as low flower- and fruit-set, low leaf area, limited photosynthesis and flower abortion. Portugal is currently the world 8th largest olive producer, with a total of $50 \times 10^{6} \mathrm{~kg}$ (FAOSTAT, 2019), and precipitation is traditionally considered the only source of available water for plant growth. In almost all the extension of the Alentejo agrarian

\footnotetext{
* Corresponding author.

E-mail address: hfraga@utad.pt (H. Fraga).
} 


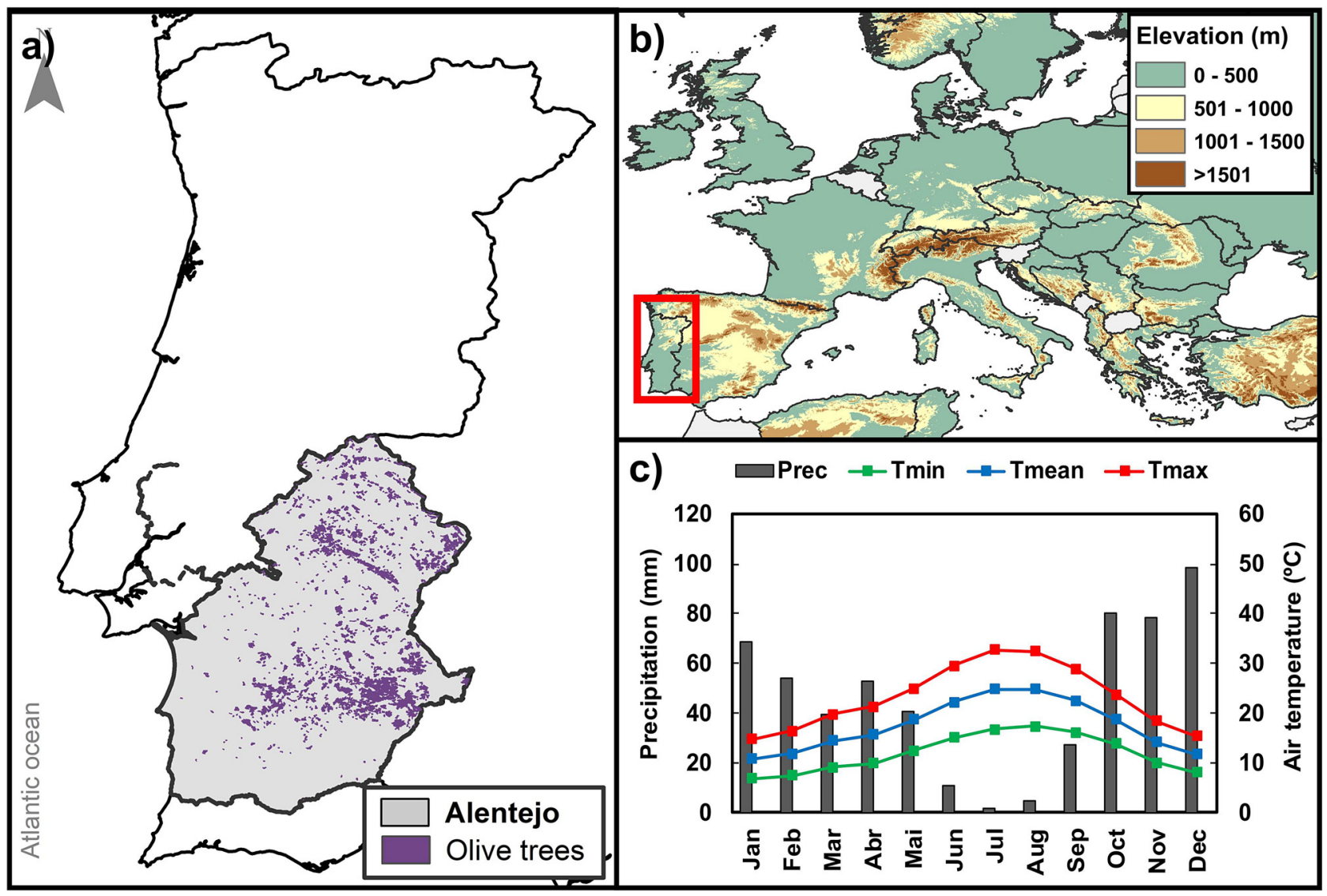

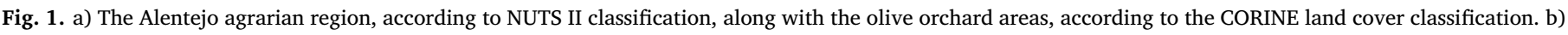

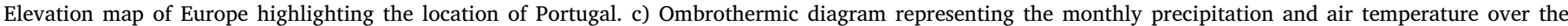

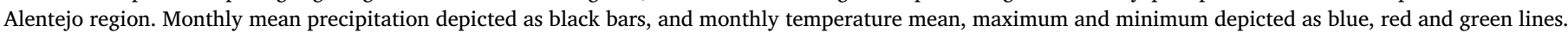

region (Fig. 1a), water stress levels can be very high, especially during the commonly warm and dry summers (Fig. 1c). Irrigating olive orchards is usually not considered, as traditional olive groves are strictly rainfed (Gomez-Rico et al., 2007). Although some intensive olive orchards are becoming more frequent, they are still a small percentage (INE, 2011).

Climate change may challenge these traditional notions (IPCC, 2013; Santos et al., 2017) due to the projected lower precipitations in Southern Europe, combined with higher temperatures, more frequent and longer heat waves and extreme droughts (IPCC, 2012). Recent studies applied to olive trees have shown that this crop can be strongly affected by climate change (Orlandi et al., 2005; Osborne et al., 2000; Ponti et al., 2014) particularly under the Mediterranean-type climates (Galán et al., 2005; Orlandi et al., 2010). For instance, rising temperatures affect the phenological timings, particularly flowering (Avolio et al., 2012; Galán et al., 2005; Orlandi et al., 2010; Osborne et al., 2001). Additionally, some studies point to a decrease in yields in some areas of the Mediterranean basin (Ponti et al., 2014). These findings motivate both further research and the development of climate change adaptation measures, namely the implementation of irrigation systems (Gomez-Rico et al., 2007; Patumi et al., 1999; Tanasijevic et al., 2014).

Water is a relatively scarce resource in Portugal, particularly in the southern and innermost areas of the country. On the other hand, water demand is increasing due to population and industrial growth, as well as to intensive agriculture water demands, amongst other factors. Hence, applying irrigation to this historically rainfed crop threatens water resources sustainability and brings additional economic, environmental and social costs. As an adaptation measure to water scarcity, smart (e.g. deficit) irrigation strategies could be implemented, providing a trade-off between environmental costs and fulfillment of plant water requirements (Tanasijevic et al., 2014). Nonetheless, the question on how much irrigation water is required to mitigate the detrimental impacts of climate change is still unanswered.

A possible solution to explore different future scenarios is the application of crop models (Ribeiro et al., 2009; Villaobos et al., 2006). Crop models can dynamically simulate crop responses to management practices (e.g. irrigation), soil properties (e.g. texture, depth), as well as crop physiological responses to atmospheric conditions (e.g. air temperature, precipitation, $\mathrm{CO}_{2}$ ). Targeting olive trees, a few models have been developed, aimed at accessing growth and development (Cesaraccio et al., 2004; De Melo-Abreu et al., 2004; Moriondo et al., 2019), or at predicting biomass growth (Maselli et al., 2012; Villaobos et al., 2006; Viola et al., 2012). Hence, by coupling crop models with high resolution climate simulations, such as those from the EUROCORDEX regional climate model experiment (Jacob et al., 2014), a regional characterization of water requirements for olive trees can be achieved.

The current study aims to characterize present and future olive tree water requirements for Alentejo and its influences on yields. These assessments are innovative for the Alentejo region and may be extended for other regions of the Mediterranean basin. The objectives are fourfold: 1) to couple a dynamic crop model with high resolution climatic simulations from four regional-global climate model chains, for current and future climate change scenarios, 2) to assess olive tree productivity changes under future climates and identify the main contributing factor to these changes; 3 ) to test suitable irrigation strategies to mitigate the impacts of climate change on yield; 4) and to analyze the potential impacts of olive tree irrigation in the future. 
Table 1

Global climate models (GCM) and regional climate models (RCM) used in this study. Each line corresponds to a combination of one GCM and one RCM (model chain).

\begin{tabular}{ll}
\hline GCM & RCM \\
\hline MPI-M-MPI-ESM-LR & CLMCOm-CCLM4-8-17 \\
IPSL-IPSL-CM5A-MR & IPSL-INERIS-WRF331 F \\
ICHEC-EC-EARTH & KNMI-RACMO22E \\
CNRM-CERFACS-CNRM-CM5 & SMHI-RCA4 \\
\hline
\end{tabular}

\section{Material and methods}

\subsection{Study region}

The Alentejo (Fig. 1a) is a large agrarian region in southern Portugal (Fig. 1b) characterized mostly by flatlands, with a relatively homogenous warm and dry climate (Fig. 1c). The Alentejo region currently has $187 \times 10^{3}$ ha of olive orchards (INE, 2019). The olive land cover is largely concentrated within three Protected Denomination of Origin (PDO) sub-regions: "Azeites do Norte Alentejano", "Azeites do Alentejo Interior" and "Azeites de Moura". The olive tree area in this region has been increasing since the 1980s (Linear Trend; LT $\sim 900$ ha year ${ }^{-1}$ ) (INE, 2019). Furthermore, the Alentejo is the most productive olive region in Portugal, with an olive oil production of around 1 million hl (INE, 2019), and an average olive yield of $\sim 850 \mathrm{~kg} \mathrm{ha}^{-1}$. Regarding the main cultivars, the Galega, Cobrançosa and Verdeal varieties can be highlighted. Olive oil in this region typically shows very low acidity levels and is often considered by national and international panels to be of exceptionally high quality.

\subsection{The crop-model simulations}

The dynamic crop model developed by Viola et al. (2012) was used herein to model olive yields. The model processes are summarised by Moriondo et al. (2015). The light interception depends on the leaf area index, while the conversion of intercepted radiation into dry matter is explained by photosynthesis and respiration. The transpiration model follows the implementation by Villalobos et al. (2000). The conversion of biomass into final yield is influenced by water stress. Indeed, dry matter partitioning and potential biomass are limited by water availability in the soil, which in turn is governed by rainfall inputs and vegetation withdrawal. The latter, is modelled with the Penman-Monteith Big Leaf model, which explicitly takes into account the effect of $\mathrm{CO}_{2}$ concentration in the photosynthesis model. All simulations were performed continuously without any re-initialisation in order examine certain carry-over effects, such as multi-year droughts. Additional information regarding this model can be found in Viola et al. (2012).

The model requires a large number of parameters describing local conditions, such as soil profile characteristics (e.g. soil hydraulic conductivity and soil porosity), technical parameters (e.g. leaf area index, crop ground cover fraction, growing season start and end) and weather daily data (precipitation, maximum and minimum temperatures, radiation, relative humidity, wind speed and $\mathrm{CO}_{2}$ concentrations). All these parameters were used as model input and are described in the subsequent sections. The model runs on a daily time step, from the start until the end of the olive tree growing season. To simulate these dates, a bioclimatic index developed by Orlandi et al. (2013) was used. This index, derived from climatic data and has been properly validated for Mediterranean olive trees (Orlandi et al., 2013), provides the annual start and end of the vegetative cycle (Orlandi et al., 2013).

\subsection{Crop model simulation inputs}

The crop model requires input datasets for i) daily weather variables, ii) soils properties, iii) topographic features, iv) management practices and v) cultivar. These data were retrieved for each olive orchard in Alentejo separately, using a geographic information system and the centroid method for extraction. For the sake of succinctness, only the average outputs for all Alentejo are shown.

\subsubsection{Meteorological variables}

The required daily meteorological variables by the crop model are: minimum and maximum air temperature (Tmin and Tmax; ${ }^{\circ} \mathrm{C}$ ), solar radiation (Rad; W. $\mathrm{m}^{-2}$ ), total precipitation (Prec; $\mathrm{mm}$ ), wind speed (WSpeed; m.s ${ }^{-1}$ ), relative humidity (RH; \%) and $\mathrm{CO}_{2}$ levels (ppmv). For the baseline period (1986-2005, 20 years), Tmin, Tmax and Prec were obtained from the E-OBS version 16 dataset (Haylock et al., 2008) and Rad, WSpeed and RH from the ERA-interim dataset (Dee et al., 2011). The baseline data corresponds to observational sources interpolated at a $\sim 25 \mathrm{~km}$ resolution. For the future period (2021-2080, 60 years), the same variables were obtained from 4 different regional climate model (RCM) simulations driven by 4 different global climate models (GCM) (Table 1), generated within the framework of the EURO-CORDEX project (Jacob et al., 2014). These gridded data are defined at $\sim 12.5 \mathrm{~km}$ spatial resolution. Additionally, data from the 4 RCM-GCM model-pairs were also retrieved for the baseline period (1986-2005) to allow a bias correction of the EURO-CORDEX data, as explained in the following section.

\subsubsection{Bias correction of the EURO-CORDEX data}

The RCM-GCM data were bias corrected following a 3-step methodology. Firstly, the RCM-GCM grid was bi-linearly interpolated to the same resolution as the E-OBS and ERA-interim grids $(\sim 25 \mathrm{~km})$. Secondly, the daily variables produced by the RCM-GCM chains were bias-corrected for 1986-2005 using the observational datasets as a reference and following the "Empirical Quantile Mapping" methodology (Cofiño et al., 2017). This methodology simply corrects the distribution of each RCM-GCM dataset based on the observations. Thirdly, the same calibration was applied to the future period (2021-2080), thus obtaining bias-corrected data for climate change assessments. This methodology was previously carried in several studies, e.g. in Fraga et al. (2019). The resulting bias-corrected gridded climatic variables are the input for the crop model.

\subsubsection{Soil and topographic characteristics}

Standard soil physical properties, such as physical-chemical properties (e.g. bulk density, albedo and $\mathrm{pH}$ ), were primarily obtained for all of the Alentejo agrarian region using information from two datasets: the global SoilGrids dataset at $250 \mathrm{~m}$ resolution (Hengl et al., 2017) and the Harmonized World Soil Database ( $\sim 1 \mathrm{~km}$ resolution) (FAO/IIASA/ ISRIC/ISSCAS/JRC, 2012). The required soil hydraulic properties for the crop model experiments (e.g. water retention capacity) were directly obtained from EU-SoilHydroGrids (Tóth et al., 2017), a newly developed fine-resolution $(250 \mathrm{~m})$ multiplayer soil hydraulic database (Brigitta et al., 2017). Regarding topography, the GTOPO30 digital elevation model (https://lta.cr.usgs.gov/GTOPO30) was used to determine elevation, aspect class and slope degree (e.g. surface runoff).

\subsubsection{Simulation scenarios}

The crop model uses the above-mentioned input variables. Previous studies indicate a general decrease in yields over Portugal under future climate conditions if no adaptation measures are implemented (Fraga et al., 2019; Ponti et al., 2014; Tanasijevic et al., 2014). Thus, the main objective would be to minimize yield losses in the future decades. To assess the role played by irrigation on olive trees under future climates, three trial runs were set: i) baseline rainfed, ii) future rainfed and iii) future irrigated. Crop model runs target the future time period and the differences between rainfed and irrigated simulation. Baseline simulations were performed as a reference to estimate the climate change signal and to normalize the future yields. Hence, crop model runs were carried over the Alentejo region for the variants i), ii) and iii). The 
obtained rainfed yield timeline for 2021-2080 was firstly normalized, using the baseline yields as a reference (relative departure from the mean of the baseline period). The same methodology was applied in the irrigated simulations.

\subsubsection{Irrigation scheme}

Automatic irrigation is set in the crop model based on a pre-defined level of the water stress index. To save water and maximize water productivity, irrigation is applied only when a certain level of plant water stress is reached. In this case, this threshold is based on the stomata closure moisture fraction of 0.78 proposed by Laio et al. (2001). Several tests were made, demonstrating that this value is well adjusted to the Portuguese conditions (not shown). Thus, this reference value was retained, also to warrant comparability with other studies. When water soil fraction drops to values below the threshold of 0.78 , irrigation is activated, simulating a dripping system with irrigation efficiency of $90 \%$ (Brouwer et al., 1989).

\subsection{Crop model validation}

The crop model developed by Viola et al. (2012) was used to model olive yields. This model was primarily validated for olive orchards in Sicily (Italy) and subsequently applied to the Mediterranean basin, providing a good agreement with the observed conditions (Fraga et al., 2020). Nonetheless, proper validation is necessary to ensure the model is well adapted to the local growing conditions in Alentejo. As such, Alentejo olive yield data were obtained from the Portuguese Statistical Office (Instituto Nacional de Estatística, INE) to allow a suitable model validation. These data correspond to yield statistics for the entire Alentejo region from 1986 onwards. Hence, a validation period was set from 1986 until 2015 to ensure a sufficiently long period (30 years). The necessary crop model input data remained the same, except for the climatic data, which was obtained from E-OBS (Haylock et al., 2008) (Tmin, Tmax and Prec) and from ERA-INTERIM (Dee et al., 2011) (RH, Rad and WSpeed). These are two well-known observation-based climatic datasets. The model runs were subsequently carried out, and the modelled yield and the observed yield were compared (see Section 3.1.).

\subsection{Crop model outputs}

Several metrics were extracted from the simulations for subsequent analysis, notably yields. Average temperature and precipitation sums were assessed, along with the potential (ETP) and actual (ETA) evapotranspiration. Two stress indicators were extracted directly from the crop model outputs: water stress (WS) and temperature stress (TS). These two stress indicators vary from 1 (no stress) to 0 (full stress). All these metrics were computed annually from the start until the end of the olive tree growing season. 11-year running means are used to analyze the temporal trends. Significance tests were carried out on the trends (Mann-Kendall trend test, $p$-value $<0.01$ ). All of the aforementioned metrics were obtained for both future scenarios (2021-2080, RCP4.5 and RCP8.5) and for all of the RCM-GCM model-chains. For the sake of conciseness, only the RCM-GCM model average, along with the model standard deviation (SD), are shown. Differences between baseline and future values were computed for all metrics, focusing on three time-periods: short-term (2021-2040); medium-term (2041-2060) and long-term (2061-2080), at a $99 \%$ confidence level, using the twosample $t$-test (only significant differences will be discussed).

\section{Results}

\subsection{Crop model validation}

Fig. 2 shows the comparison between observed and simulated yields for the recent period (1986-2015). It is clear that the model developed by Viola et al. (2012) is able to properly replicate the observed yields. The simulation shows a high correlation with observed values $(r=0.81)$. Furthermore, the simulation shows MAE of $336 \mathrm{~kg} / \mathrm{ha}$, which can be considered a moderate error margin. However, it should be taken into account that these observational yields derive from statistical sources (census) and apply to the Alentejo territory as a whole. Despite the degree of uncertainty in the observational source, which may partially explain to the differences found between observed and simulated yields, the simulated yields show a strong correlation with observations, statistically significant at $p<0.001$.

\subsection{Future climatic conditions in the olive tree growing season}

The mean temperature in Alentejo (Fig. 3a) is projected to significantly increase (Mann Kendall trend test, $p$-value $<0.01$ ) in the olive tree growing season, with stronger trends in RCP8.5 $\left(0.04{ }^{\circ} \mathrm{C}\right.$ $\left.\mathrm{yr}^{-1}\right)$ than in $\mathrm{RCP} 4.5\left(0.02{ }^{\circ} \mathrm{C} \mathrm{yr}^{-1}\right)$. With respect to the baseline period, projections hint at a significant increase in mean temperature of up to $2{ }^{\circ} \mathrm{C}$ compared to the reference period (Fig. 3b). Changes will be more evident in the last time sub-period (2061-2080) and for RCP8.5. RCM-GCM SD shows homogenous values along the time-series, with a range of approximately $0.5^{\circ} \mathrm{C}$. Regarding the growing season precipitation sum (Fig. 3c), future changes are not as clear as for temperature, showing large fluctuations throughout the time series. Nonetheless, a decrease is apparent, with stronger implications on RCP8.5 (-0.4 $\left.\mathrm{mm} \mathrm{yr}^{-1}\right)$ compared to RCP4.5 $\left(-0.2 \mathrm{~mm} \mathrm{yr}^{-1}\right)$. Significant differences to baseline show decreases of -70 to $-80 \mathrm{~mm}$ in $2021-2040$, -75 to $-90 \mathrm{~mm}$ in $2041-2060$, and -80 to $-90 \mathrm{~mm}$ in RCP4.5 and RCP8.5, respectively (Fig. 3d). SD range shows values around $100 \mathrm{~mm}$, particularly in the earlier period, which reveals strong inter-model variability. ETP shows similar behavior to temperature (Fig. 3e), with similar increasing trend under both future scenarios $\left(0.8 \mathrm{~mm} \mathrm{yr}^{-1}\right)$. Until 2080, ETP is projected to significantly increase from 40 to $50 \mathrm{~mm}$ (Fig. 3f). SD shows stronger values by the end of the future period (2041-2080). Regarding ETA (Fig. 3g), this metric shows a decreasing trend, though it is non-significant, decreasing from -50 to -70 until 2080, under both future scenarios (Fig. 3h). SD shows higher ranges in the beginning of the future period.

\subsection{Yield projections and stress forcing factors}

In order to analyze the changes in yield over time, the simulated yield values are shown with respect to their relative difference (in percentage) to the baseline period mean yields. Overall, simulated yields show a decreasing trend, with stronger reduction in RCP8.5 $\left(-0.04 \% \mathrm{yr}^{-1}\right)$ than in RCP4.5 $5\left(-0.02 \% \mathrm{yr}^{-1}\right)$ (Fig. 4a). Simulated olive tree yields over Alentejo show strong variability throughout the future period (Fig. 4b), but particularly in the short-term (2021-2040). Regarding the accumulated yield losses over the entire future period (from 2021 to 2080) (Fig. 4c), projections indicate large decreases in productivity over Alentejo, reaching -8 to $-10 \mathrm{t} / \mathrm{ha}$ on average for RCP4.5 and RCP8.5, respectively. The SD of the accumulated yield change shows a sustained increase in spread, reaching $8 \mathrm{t} / \mathrm{ha}$ by 2080 . Thus, large productivity losses are accumulated over time.

These negative impacts of climate change on olive tree yields are linked to the enhanced stress conditions in the future climates. Fig. $5 \mathbf{a}$ and $\mathbf{b}$ show the water and temperature stress (WS + TS) difference between future (RCP4.5 and 8.5, respectively) and baseline, along with the decrease in yields. The curves of WS + TS show a very similar pathway to the yields (negative percentages in WS + TS indicate increase in stress), highlighting the influence of these two stresses on olive trees. Hence, the synergetic impacts of the enhanced stress conditions on yield becomes noticeable, being the coefficient of correlation between this two curves very high $(r>0.81)$ in both future scenarios. Water stress has by far the largest impact on future yields, closely mimicking the yield change curve, while temperature stress shows a 


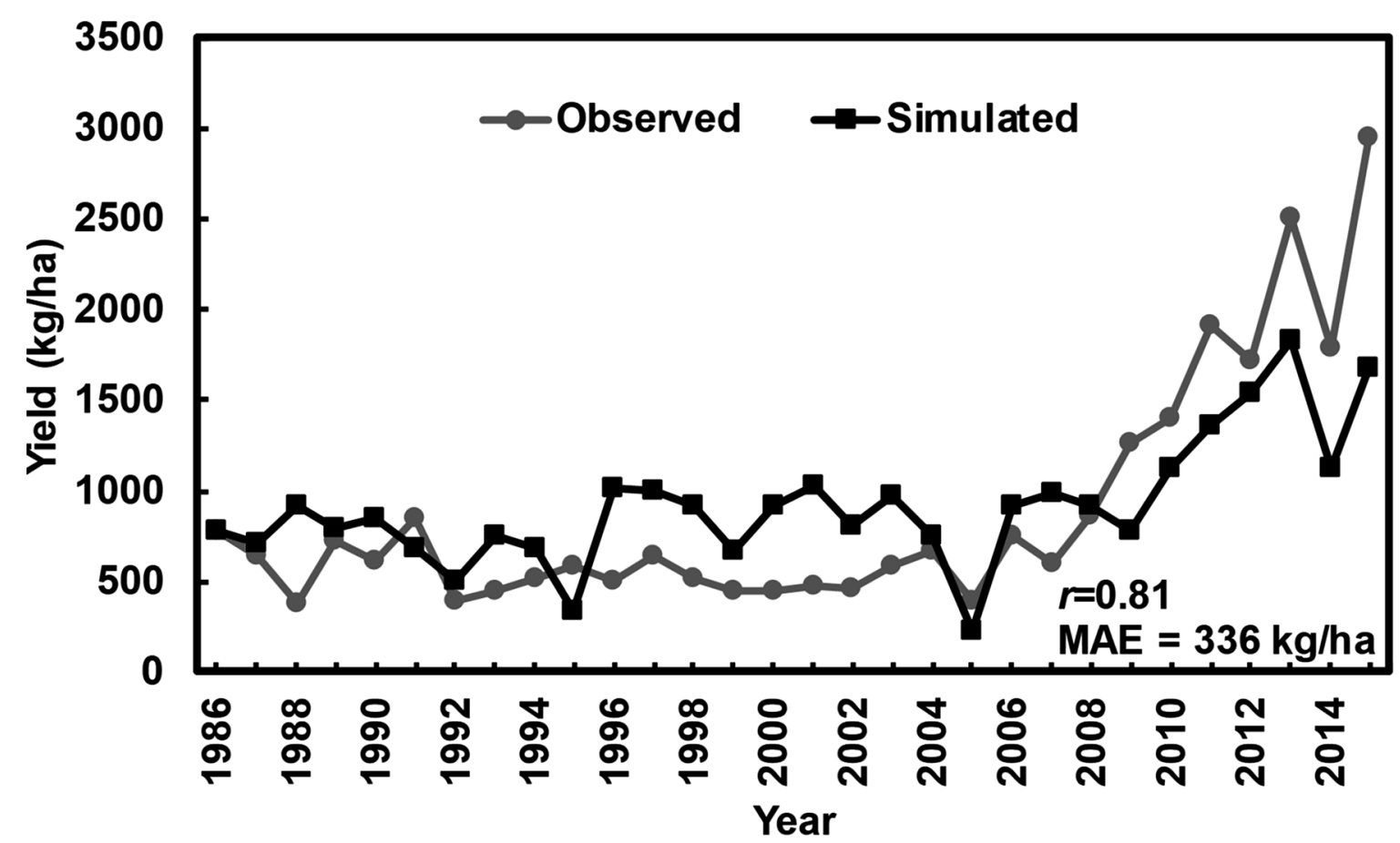

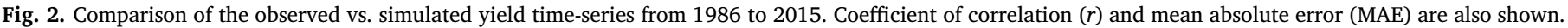

generally small but linear increasing impact with time. While these two metrics essentially reflect the future temperature and precipitation conditions, both WS and TS also take into account extreme conditions, as they do include in their definition extreme temperature and precipitation thresholds.

\subsection{Irrigation as an adaptation measure}

Henceforth, irrigation is applied as a possible adaptation measure against the decreasing yield projected for the future (see section 2.3.6). Fig. 6 a shows the future yield anomalies, but now with the application of irrigation. Comparing Fig. $4 \mathbf{a}$ and Fig. 6a, the changes in future yield by introducing irrigation are quite clear. While some inter-annual variability is present, the yield anomaly time-series remains close to zero (difference between future and baseline yields of $\pm 1 \%$ ), revealing the effectivity of this climate change adaptation measure. In fact, yield is projected to slightly increase (linear trend of $0.05 \% \mathrm{yr}^{-1}$ ), under both future scenarios. The outcomes from the four climate models show very similar patterns, but with relatively low $\mathrm{SD}$. When compared to the non-irrigated simulation (Fig. 3a), it is clear that the strongest benefits of irrigation will be more prominent over the last period (2061-2080), since the increases in yield are greater during this time-frame. The accumulated yield difference (Fig. 6c), shows that yield losses will be close to zero, on average, if irrigation is applied, though the uncertainty tied to this assessment increases with time, ranging from -3 to $2 \mathrm{t} / \mathrm{ha}$ in 2080 .

Fig. 7a, shows the necessary irrigation amounts $(\mathrm{mm})$ to obtain these yield levels under future climate conditions. Under RCP4.5, the necessary irrigation level to counteract the negative effects of climate change is of approximately $60 \mathrm{~mm}$, whereas these values can reach $\sim 80 \mathrm{~mm}$ in RCP8.5. However, the SD associated to this metric is quite large, as these values may reach $80 \mathrm{~mm}$ in RCP4.5 and $120 \mathrm{~mm}$ in RCP8.5. Hence, by applying these irrigation levels, yield losses can be greatly alleviated. Based on these findings, a new metric was developed taking into account the required irrigation amounts and the absolute value of the precipitation decrease under future climate change scenarios (future minus baseline: $\Delta$ ), defined as the ratio between irrigation and the $\Delta$ of precipitation. The required irrigation ranges from
0.6-1 times the loss of precipitation (Fig. 7b), although it may reach up to 2 times when considering climate model uncertainty. These results highlighting the need to estimate for water availability under future climate conditions, which will be dependent on the choice of future scenario and climate model chain. Therefore, in order to maintain current yield levels, the irrigation needed in future decades may be larger than the projected precipitation decrease for the same period.

\section{Discussion}

The present study assesses the importance of irrigation as a potential climate change adaptation measure to ensure the future sustainability of olive tree yields in Alentejo, the most important olive tree growing region in Portugal. A dynamic process-based crop model was used to simulate baseline and future olive tree yields in Alentejo, revealing significant yield decreases over this region. Future projections also depict an increase in temperature and a decrease in precipitation over this region, which will lead to significantly enhanced water and temperature stresses, partially explaining these outcomes. As a strong candidate adaptation measure, deficit irrigation was tested for the future climates. Irrigation was only applied when a certain water stress level was reached (cf. section 2.3.5), mimicking a high efficiency water use strategy, in an attempt to maintain current yield levels in the future. The results indicate that irrigation is indeed a viable adaptation strategy, but irrigation requirements may exceed the projected precipitation deficits.

The amounts of irrigation requirements under climate change range from 60 from $85 \mathrm{~mm}$ (RCP4.5 and RCP8.5), with an uncertainty of \pm $25 \mathrm{~mm}$, depending on the climate model. These values are in line with projections from Tanasijevic et al. (2014) for southern Europe. These irrigation requirements correspond to $0.6-1$ times (RCP4.5 and RCP8.5 average) the water lost by the decrease in future precipitation, but these values may reach 2 times when considering the climate model spread, pointing to the synergetic effect of higher temperature and lower precipitation on olive yields. Nevertheless, if irrigation (scheduling and amounts) and water stress levels are carefully monitored and controlled (Marino et al., 2016), the negative impacts of climate change can be largely circumvented. To address these issues, in real life farming 


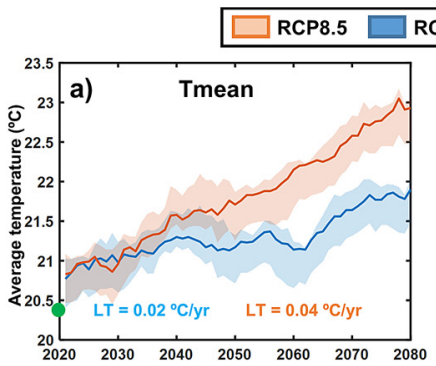

$$
\text { CP4.5 Recent-past }
$$
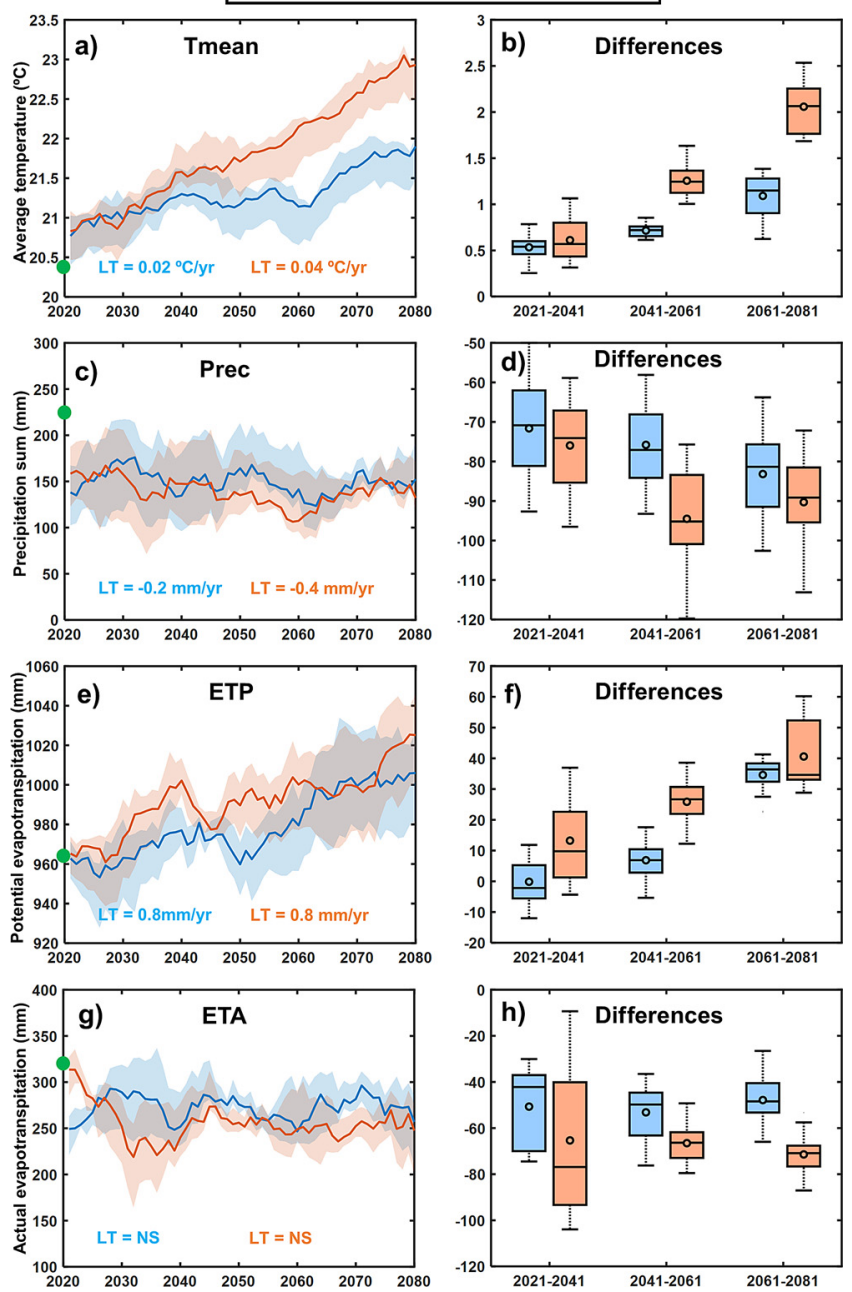

Fig. 3. Left panel: a) growing season mean temperature (Tmean), c) precipitation sum (Prec), e) potential evapotranspiration (ETP) and g) actual evapotranspiration (ETA) over the olive orchard areas of Alentejo from 2021 to 2080 with an 11-year running mean. Green dot indicates the average for the recent past period (1986-2010). Right panel: Box plots representing the differences between the future periods (2021-2040, 2041-2060 and 2061-2080) and the recent-past (1986-2010) for the variables of the corresponding left panel. Both future scenarios are represented (blue colors for RCP4.5, red colors for RCP8.5). Shaded area corresponds to the climate model standard-deviation range and LT corresponds to the linear trend.

conditions, olive growers need to plan the installation of suitable irrigation systems and use sensors/instruments to regularly monitor plant water stress status (Marino et al., 2016). These monitoring techniques should be combined with deficit irrigation procedures so as to preserve water resources and increase water use efficiency (Gomez-Rico et al., 2007). A reduction of water usage in agriculture through improved irrigation management is a major concern when envisioning agriculture sustainability in the future (Marino et al., 2016). Traditional irrigation practices should be replaced by less water demanding practices, such as partial root-zone drying (Araujo et al., 2019; Ghrab et al., 2013; Wang et al., 2017).

Another challenge to the proposed adaptation measure will be providing sufficient water during the necessary irrigation periods, which overlap with the driest period of the year (Torres et al., 2019). The construction and maintenance of water reservoirs for agriculture is crucial to meet the required irrigation demands (Batista et al., 2001). In Portugal, over the last decades, a significant effort has been made to create a large artificial reservoir in the Alentejo region (Alqueva dam),
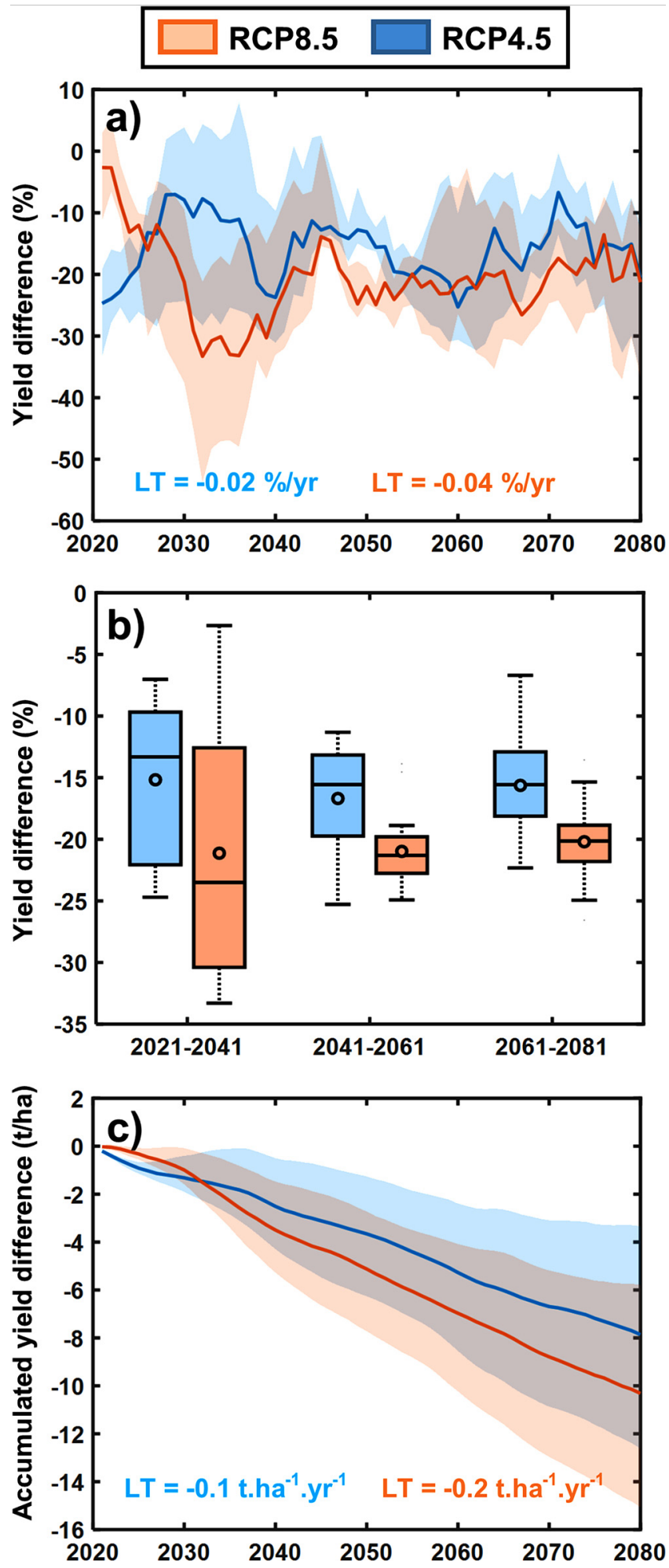

Fig. 4. a) Time series simulated yield differences (\%) in respect to the recent past period (1986-2010) with an 11-year running mean, along with the respective linear trends. b) Box-plots representing the yield differences (\%) in short-, medium- and long-term periods (2021-2040, 2041-2060 and 2061-2080, respectively). c) Accumulated annual yield differences in the full time period (2021 to 2080) with an 11-year running mean. Both future scenarios are represented (blue colors for RCP4.5, red colors for RCP8.5). Shaded area corresponds to the climate model standard-deviation range and LT corresponds to the linear trend. 

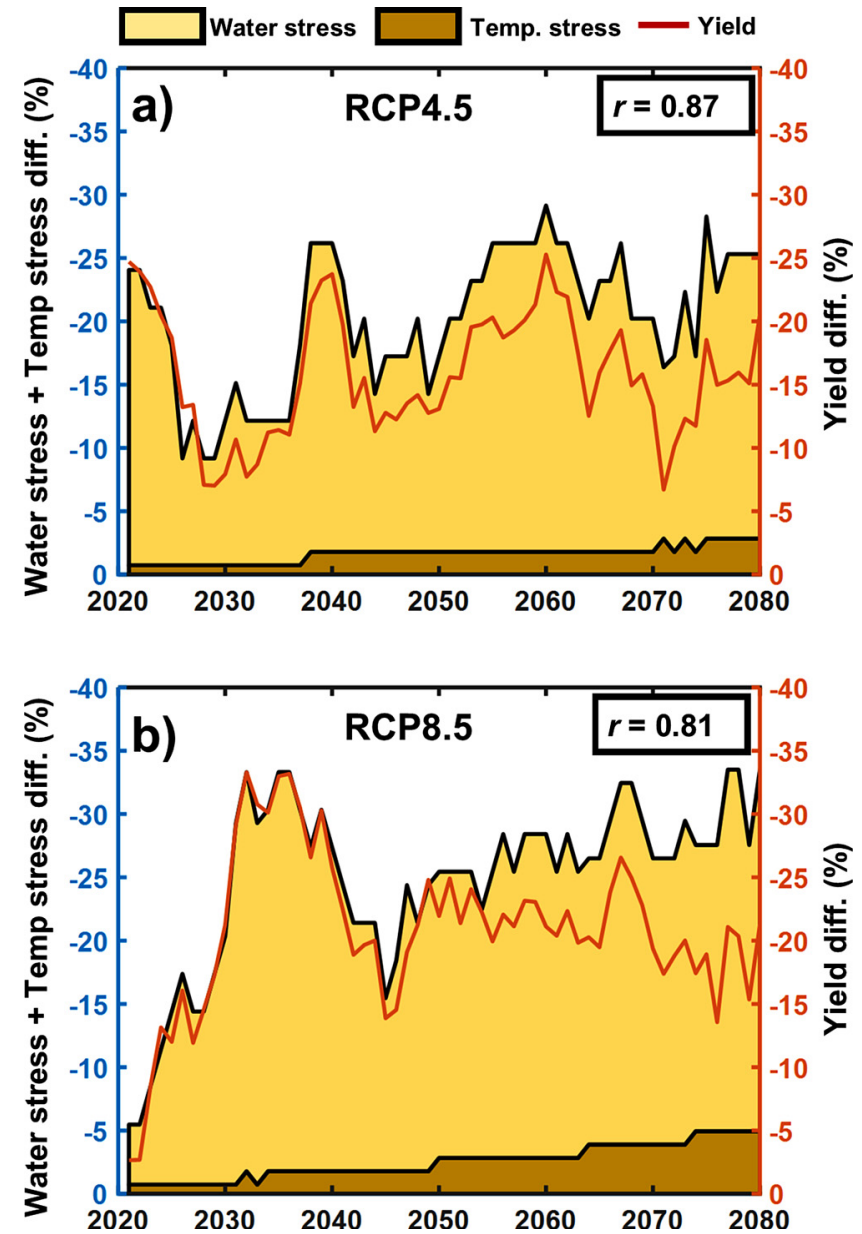

Fig. 5. Pilled cart of the water stress and temperature stress differences for the a) RCP4.5 and b) RCP8.5 scenarios, in respect to the recent-past period (19862010) with an 11-year running mean. Also shown in the yield difference (as Fig. 2a but inverted axis). The correlation coefficient between the two curves (water stress / temp stress and yield differences) is indicated in the upper right corner.

used for both hydroelectric power generation and irrigation, with a very large water storage capacity of $3150 \times 10^{6} \mathrm{~m}^{3}$. Nonetheless, water conservation should be a priority and decision-makers must carefully consider the effects of increasing agricultural water usage, including the sustainability of the national water resources (EEA, 2009).

Given the scarcity of water in this region, other adaptation measures should be foreseen to improve crop performance under more adverse conditions (Fraga et al., 2018). To address this issue, growers should promote higher water use efficiencies (Trentacoste et al., 2015). The selection of more drought resilient olive tree varieties (Bacelar et al., 2006) may be of great importance. In effect, the usefulness of irrigation will also depend on the varietal response to water stress. As an example, the "Arbequina" variety is one of the more widely used cultivars worldwide, and is considered to be very drought tolerant (Bacelar et al., 2006). Hence, the varietal response to drought, under climate change conditions, should be explored (Larbi et al., 2015).

Other aspects that can improve water use efficiency comprise adjustments to traditional tillage systems and soil management practices, considering specific cover crops (Sastre et al., 2018) or even mulching (Fraga and Santos, 2018). The combination of all management techniques to adapt to climate change may actually improve water use efficiency and provide a compromise solution between environment, plant water requirements and economic costs for growers. It should be noted that the crop model simulations already take into consideration the
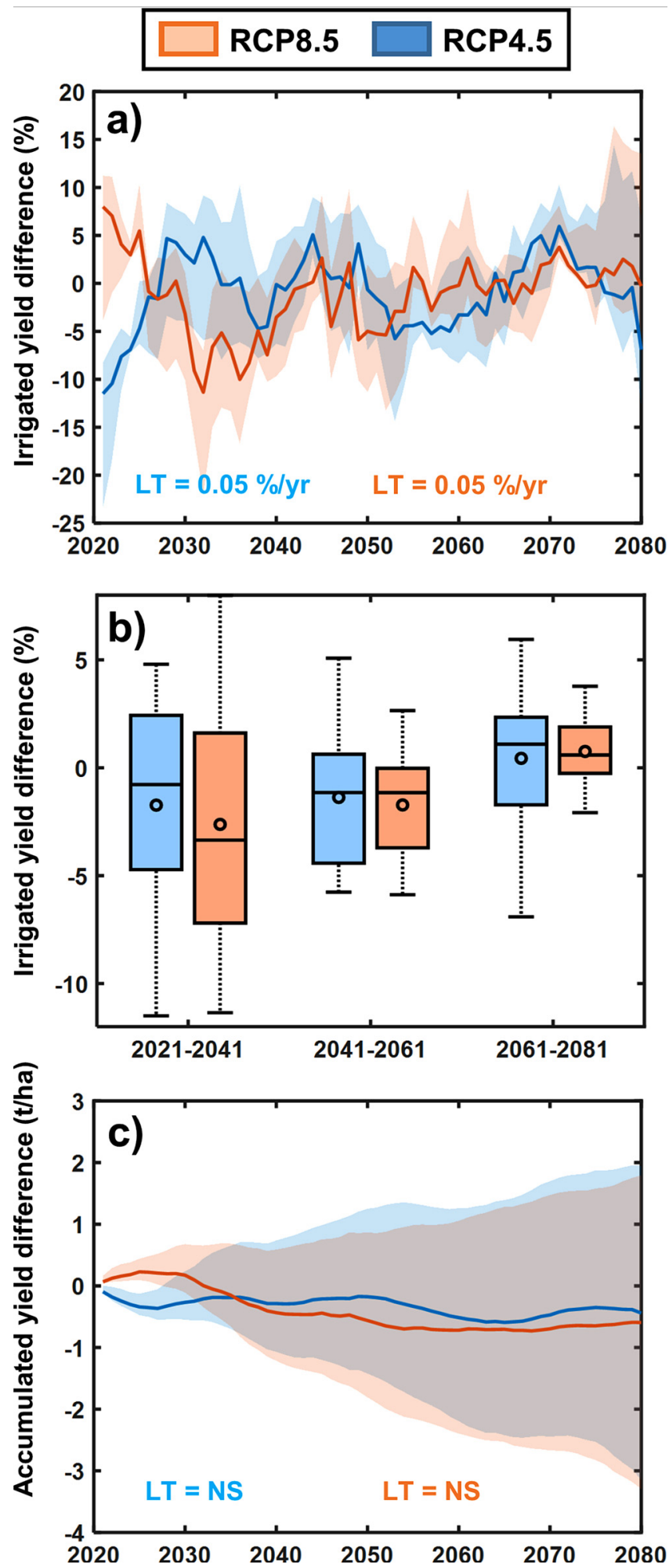

Fig. 6. a) Time series simulated yield differences with irrigation (\%) in respect to the recent past period (1986-2010) with an 11-year running mean, along with the respective linear trends. b) Box-plots representing the yield differences with irrigation (\%) in short-, medium- and long-term periods (2021-2040, 2041-2060 and 2061-2080, respectively). c) Accumulated annual yield differences with irrigation in the full time period (2021 to 2080) with an 11-year running mean. Both future scenarios are represented (blue colors for RCP4.5, red colors for RCP8.5). Shaded area corresponds to the climate model standarddeviation range and LT corresponds to the linear trend. 

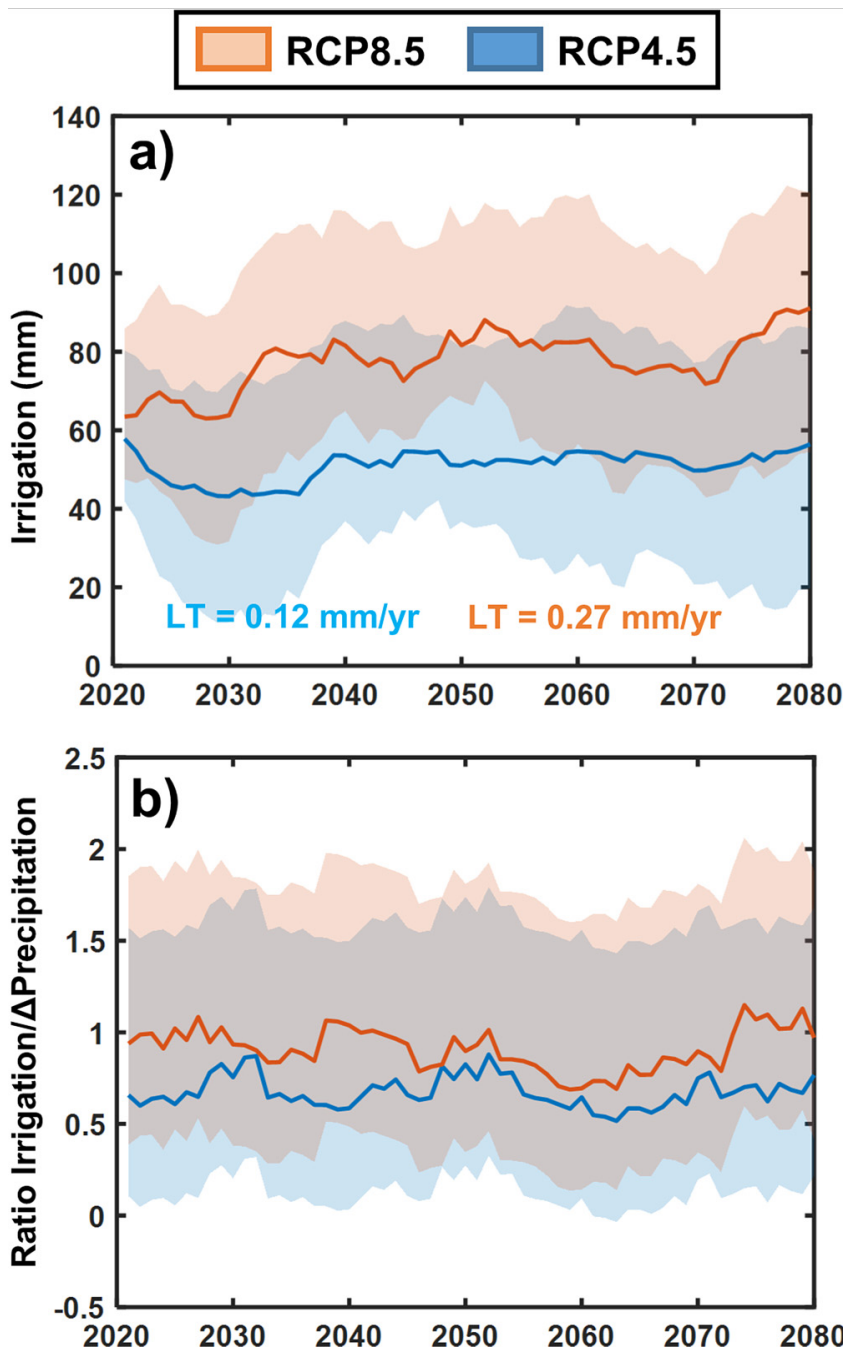

Fig. 7. a) Amount of irrigation ( $\mathrm{mm}$ ) required to maintain yield levels similar to the recent-past period with an 11-year running mean (mean difference within $+/-1 \%$ ). b) Ratio of irrigation to precipitation delta (difference of future and recent past precipitation levels). Both future scenarios are represented (RCP4.5 and RCP8.5). Shaded area corresponds to the climate model standard-deviation range and LT corresponds to the linear trend.

beneficial effects of higher $\mathrm{CO}_{2}$ atmospheric concentrations in the future. It is known that the increase in $\mathrm{CO}_{2}$ levels under future climates may bring positive effects for plants, particularly increasing biomass under $\mathrm{CO}_{2}$ enriched environments (Biel et al., 2008). This effect partially counteracts the climate change detrimental impacts resulting from the rainfall decrease, and was taken into account by the crop model, thus increasing the robustness of the present study results.

\section{Conclusions}

The present study showed that one possible adaptation measure, i.e. irrigation, may significantly alleviate the detrimental impacts of climate change on olive yields, ensuring the future sustainability of the olive industry in Portugal. However, irrigation is always strictly dependent on water availability at a local scale, which may be problematic for some regions in the Mediterranean basin, such as Alentejo. Hence, forthcoming studies on olive trees adaptation strategies to climate change should focus on alternative or complementary measures, such as microclimate selection, varietal and clonal selection, soil management, cover crops, mulching, fertilization, amongst others. Given the future projections of olive yields for the Alentejo region, the implementation of these adaptation measures is critical for the future sustainability of this sector.

\section{Declaration of interests}

The authors declare that they have no known competing financial interests or personal relationships that could have appeared to influence the work reported in this paper.

\section{Acknowledgements}

Helder Fraga thanks the FCT - Portuguese Foundation for Science and Technology for contract CEECIND/00447/2017. This study was carried out under the CoaClimateRisk FCT Project (COA/CAC/0030/ 2019). This work was also supported by National Funds by FCT under the project UIDB/04033/2020. JGP thanks the AXA Research Fund for support. We acknowledge the World Climate Research Programme's Working Group on Regional Climate and the Working Group on Coupled Modeling, former coordinating body of CORDEX and responsible panel for CMIP5. We also thank the climate modeling groups for producing and making available their model output. We acknowledge the E-OBS data set from the EU-FP6 project ENSEMBLES (http:// ensembles-eu.metoffice.com) and the data providers in the ECA\&D project (http://www.ecad.eu).

\section{References}

Arampatzis, G., Hatzigiannakis, E., Pisinaras, V., Kourgialas, N., Psarras, G., Kinigopoulou, V., Panagopoulos, A., Koubouris, G., 2018. Soil water content and olive tree yield responses to soil management, irrigation, and precipitation in a hilly Mediterranean area. J Water Clim Change 9, 672-678.

Araujo, M., de Oliveira, J.M.P.F., Santos, C., Moutinho-Pereira, J., Correia, C., Dias, M.C., 2019. Responses of olive plants exposed to different irrigation treatments in combination with heat shock: physiological and molecular mechanisms during exposure and recovery. Planta 249, 1583-1598.

Avolio, E., Orlandi, F., Bellecci, C., Fornaciari, M., Federico, S., 2012. Assessment of the impact of climate change on the olive flowering in Calabria (southern Italy). Theor Appl Clim 107, 531-540.

Bacelar, E.A., Santos, D.L., Moutinho-Pereira, J.M., Goncalves, B.C., Ferreira, H.F., Correia, C.M., 2006. Immediate responses and adaptative strategies of three olive cultivars under contrasting water availability regimes: changes on structure and chemical composition of foliage and oxidative damage. Plant Sci. 170, 596-605.

Batista, S., Silva, E., Cerejeira, M., Silva-Fernandes, A., 2001. Exposure of ground water to alachlor, atrazine and metolachlor in maize areas of Ribatejo and Oeste (Portugal). Toxicol. Environ. Chem. 79, 223-232.

Biel, C., de Herralde, F., Save, R., Evans, R.Y., 2008. Effects of CO2 atmospheric fertilization on greenhouse production of olive trees (Olea europaea L.' Arbequina'). Eur. J. Hortic. Sci. 73, 227-230.

Brigitta, T., Melanie, W., László, P., Tomislav, H., 2017. 3D soil hydraulic database of Europe at $250 \mathrm{~m}$ resolution. Hydrol. Process. 31, 2662-2666.

Brouwer, C., Prins, K., Heibloem, M., 1989. Irrigation Water Management: Irrigation Scheduling. Training Manual no. 4. Food and Agriculture Organization of the United Nations, Rome, Italy.

Cesaraccio, C., Spano, D., Snyder, R.L., Duce, P., 2004. Chilling and forcing model to predict bud-burst of crop and forest species. Agric. For. Meteorol. 126, 1-13.

Cofiño, A.S., Bedia, J., Iturbide, M., Vega, M., Herrera, S., Fernández, J., Frías, M.D. Manzanas, R., Gutiérrez, J.M., 2017. The ECOMS User Data Gateway: Towards Seasonal Forecast Data Provision and Research Reproducibility in the Era of Climate Services. Climate Services.

De Melo-Abreu, J.P., Barranco, D., Cordeiro, A.M., Tous, J., Rogado, B.M., Villalobos, F.J., 2004. Modelling olive flowering date using chilling for dormancy release and thermal time. Agric. For. Meteorol. 125, 117-127.

Dee, D.P., Uppala, S.M., Simmons, A.J., Berrisford, P., Poli, P., Kobayashi, S., Andrae, U., Balmaseda, M.A., Balsamo, G., Bauer, P., Bechtold, P., Beljaars, A.C.M., van de Berg, L., Bidlot, J., Bormann, N., Delsol, C., Dragani, R., Fuentes, M., Geer, A.J., Haimberger, L., Healy, S.B., Hersbach, H., Hólm, E.V., Isaksen, L., Kållberg, P. Köhler, M., Matricardi, M., McNally, A.P., Monge-Sanz, B.M., Morcrette, J.J., Park, B.K., Peubey, C., de Rosnay, P., Tavolato, C., Thépaut, J.N., Vitart, F., 2011. The ERAInterim reanalysis: configuration and performance of the data assimilation system. Q. J1 R. met. Soc. 137, 553-597.

EEA, 2009. Water Resources Across Europe - Confronting Water Scarcity and Drought. European Environment Agency Report n2, Copenhagen, Denmark pp60.

FAO/IIASA/ISRIC/ISSCAS/JRC, 2012. Harmonized World Soil Database (version 1.2), FAO, Rome, Italy and IIASA, Laxenburg, Austria.

FAOSTAT, 2019. Agricultural Statistics - Crops - http://www.fao.org/faostat, Food and Agriculture Organization of the United Nations.

Fraga, H., Santos, J.A., 2018. Vineyard mulching as a climate change adaptation measure: 
future simulations for Alentejo. Portugal. Agric Sys 164, 107-115.

Fraga, H., García de Cortázar Atauri, I., Santos, J.A., 2018. Viticultural irrigation demands under climate change scenarios in Portugal. Agric. Water Manag. 196, 66-74.

Fraga, H., Pinto, J.G., Santos, J.A., 2019. Climate change projections for chilling and heat forcing conditions in European vineyards and olive orchards: a multi-model assessment. Clim. Change 152, 179-193.

Fraga, H., Pinto, J.G., Viola, F., Santos, J.A., 2020. Climate change projections for olive yields in the Mediterranean Basin. Int. J. Clim. 40, 769-781.

Galán, C., García-Mozo, H., Vázquez, L., Ruiz, L., de la Guardia, C.D., Trigo, M.M., 2005. Heat requirement for the onset of the Olea europaea L. Pollen season in several sites in Andalusia and the effect of the expected future climate change. Int. J. Biometeorol. 49, 184-188.

Ghrab, M., Gargouri, K., Bentaher, H., Chartzoulakis, K., Ayadi, M., Ben Mimoun, M., Masmoudi, M.M., Ben Mechlia, N., Psarras, G., 2013. Water relations and yield of olive tree (cv. Chemlali) in response to partial root-zone drying (PRD) irrigation technique and salinity under arid climate. Agric. Water Manag. 123, 1-11.

Gomez-Rico, A., Salvador, M.D., Moriana, A., Perez, D., Olmedilla, N., Ribas, F., Fregapane, G., 2007. Influence of different irrigation strategies in a traditional Cornicabra cv. Olive orchard on virgin olive oil composition and quality. Food Chem. $100,568-578$.

Haylock, M.R., Hofstra, N., Klein Tank, A.M.G., Klok, E.J., Jones, P.D., New, M., 2008. A European daily high-resolution gridded data set of surface temperature and precipitation for 1950-2006. J. Geophys. Res. 113, D20119.

Hengl, T., Mendes de Jesus, J., Heuvelink, G.B.M., Ruiperez Gonzalez, M., Kilibarda, M., Blagotić, A., Shangguan, W., Wright, M.N., Geng, X., Bauer-Marschallinger, B., Guevara, M.A., Vargas, R., MacMillan, R.A., Batjes, N.H., Leenaars, J.G.B., Ribeiro, E., Wheeler, I., Mantel, S., Kempen, B., 2017. SoilGrids250m: global gridded soil information based on machine learning. PLoS One 12, e0169748.

Iglesias, A., Garrote, L., 2015. Adaptation strategies for agricultural water management under climate change in Europe. Agric. Water Manag. 155, 113-124.

INE, 2011. O Uso Da Água Na Agricultura - Instituto Nacional De Estatística, I.P, 93 Pp.

INE, 2019. Main Crops Yield (kg/ Ha) by Geographic Localization (Agrarian Region) and Specie; Annual - https://www.ine.pt/, Instituto Nacional De Estatística, I.P.

IPCC, 2012. Managing the risks of extreme events and disasters to advance climate change adaptation. In: Field, C.B., Barros, V., Stocker, T.F., Qin, D., Dokken, D.J., Ebi, K.L., Mastrandrea, M.D., Mach, K.J., Plattner, G.-K., Allen, S.K., Tignor, M., Midgley, P.M. (Eds.), A Special Report of Working Groups I and II of the Intergovernmental Panel on Climate Change. Cambridge University Press, Cambridge, UK, and New York, NY, USA, pp. 582.

IPCC, 2013. Climate change 2013: the physical science basis. In: Stocker, T.F., Qin, D., Plattner, G.-K., Tignor, M., Allen, S.K., Boschung, J., Nauels, A., Xia, Y., Bex, V., Midgley, P.M. (Eds.), Contribution of Working Group I to the Fifth Assessment Report of the Intergovernmental Panel on Climate Change. Cambridge University Press, Cambridge, United Kingdom and New York, NY, USA, pp. 1535.

Jacob, D., Petersen, J., Eggert, B., Alias, A., Christensen, O.B., Bouwer, L.M., Braun, A., Colette, A., Deque, M., Georgievski, G., Georgopoulou, E., Gobiet, A., Menut, L., Nikulin, G., Haensler, A., Hempelmann, N., Jones, C., Keuler, K., Kovats, S., Kroner, N., Kotlarski, S., Kriegsmann, A., Martin, E., van Meijgaard, E., Moseley, C., Pfeifer, S., Preuschmann, S., Radermacher, C., Radtke, K., Rechid, D., Rounsevell, M., Samuelsson, P., Somot, S., Soussana, J.F., Teichmann, C., Valentini, R., Vautard, R., Weber, B., Yiou, P., 2014. EURO-CORDEX: new high-resolution climate change projections for European impact research. Reg. Environ. Change 14, 563-578.

Laio, F., Porporato, A., Ridolfi, L., Rodriguez-Iturbe, I., 2001. Plants in water-controlled ecosystems: active role in hydrologic processes and response to water stress: II. Probabilistic soil moisture dynamics. Adv. Water Resour. Prot. 24, 707-723.

Larbi, A., Vazquez, S., El-Jendoubi, H., Msallem, M., Abadia, J., Abadia, A., Morales, F., 2015. Canopy light heterogeneity drives leaf anatomical, eco-physiological, and photosynthetic changes in olive trees grown in a high-density plantation. Photosynth Res 123, 141-155.

Marino, G., Pernice, F., Marra, F.P., Caruso, T., 2016. Validation of an online system for the continuous monitoring of tree water status for sustainable irrigation managements in olive (Olea europaea L.). Agric. Water Manag. 177, 298-307.

Maselli, F., Chiesi, M., Brilli, L., Moriondo, M., 2012. Simulation of olive fruit yield in
Tuscany through the integration of remote sensing and ground data. Ecol Model 244, $1-12$.

Moriondo, M., Ferrise, R., Trombi, G., Brilli, L., Dibari, C., Bindi, M., 2015. Modelling olive trees and grapevines in a changing climate. Environ. Model. Softw. 72, $387-401$.

Moriondo, M., Leolini, L., Brilli, L., Dibari, C., Tognetti, R., Giovannelli, A., Rapi, B. Battista, P., Caruso, G., Gucci, R., Argenti, G., Raschi, A., Centritto, M., Cantini, C., Bindi, M., 2019. A simple model simulating development and growth of an olive grove. Eur. J. Agron. 105, 129-145.

Orlandi, F., Ruga, L., Romano, B., Fornaciari, M., 2005. Olive flowering as an indicator of local climatic changes. Theor Appl Clim 81, 169-176.

Orlandi, F., Garcia-Mozo, H., Galán, C., Romano, B., de la Guardia, C.D., Ruiz, L., del Mar Trigo, M., Dominguez-Vilches, E., Fornaciari, M., 2010. Olive flowering trends in a large Mediterranean area (Italy and Spain). Int. J. Biometeorol. 54, 151-163.

Orlandi, F., Avolio, E., Bonofiglio, T., Federico, S., Romano, B., Fornaciari, M., 2012. Potential shifts in olive flowering according to climate variations in Southern Italy. Met. Appl. 20, 497-503.

Orlandi, F., Garcia-Mozo, H., Dhiab, A.B., Galán, C., Msallem, M., Romano, B., Abichou, M., Dominguez-Vilches, E., Fornaciari, M., 2013. Climatic indices in the interpretation of the phenological phases of the olive in mediterranean areas during its biological cycle. Clim. Change 116, 263-284.

Osborne, C.P., Chuine, I., Viner, D., Woodward, F.I., 2000. Olive phenology as a sensitive indicator of future climatic warming in the Mediterranean. Pl. Cell Envir. 23, $701-710$.

Osborne, C.P., Chuine, I., Viner, D., Woodward, F.I., 2001. Olive phenology as a sensitive indicator of future climatic warming in the Mediterranean. Plant Cell Environ. 23, 701-710.

Patumi, M., d'Andria, R., Fontanazza, G., Morelli, G., Giorio, P., Sorrentino, G., 1999. Yield and oil quality of intensively trained trees of three cultivars of olive (Olea europaea L.) under different irrigation regimes. J. Hortic. Sci. Biotechnol. 74, 729-737.

Ponti, L., Gutierrez, A.P., Ruti, P.M., Dell'Aquila, A., 2014. Fine-scale ecological and economic assessment of climate change on olive in the Mediterranean Basin reveals winners and losers. Proc Natl Acad Sci U S A 111, 5598-5603.

Ribeiro, H., Cunha, M., Abreu, I., 2009. A bioclimatic model for forecasting olive yield. J. Agric. Sci. 147, 647-656.

Santos, J.A., Costa, R., Fraga, H., 2017. Climate change impacts on thermal growing conditions of main fruit species in Portugal. Clim. Change 140, 273-286.

Sastre, B., Bienes, R., García-Díaz, A., 2018. How Much Is Soil Volumetric Water Content Influenced by Cover Crops in an Olive Grove in Central Spain?, $1199 \mathrm{Ed}$. International Society for Horticultural Science (ISHS), Leuven, Belgium. pp. 345-350.

Tanasijevic, L., Todorovic, M., Pereira, L.S., Pizzigalli, C., Lionello, P., 2014. Impacts of climate change on olive crop evapotranspiration and irrigation requirements in the Mediterranean region. Agric. Water Manag. 144, 54-68.

Torres, I., Sanchez, M.T., Benlloch-Gonzalez, M., Perez-Marin, D., 2019. Irrigation decision support based on leaf relative water content determination in olive grove using near infrared spectroscopy. Biosys. Eng. 180, 50-58.

Tóth, B., Weynants, M., Pásztor, L., Hengl, T., 2017. 3D soil hydraulic database of Europe at $250 \mathrm{~m}$ resolution. Hydrol. Processes 31, 2662-2666.

Trentacoste, E.R., Puertas, C.M., Sadras, V.O., 2015. Effect of irrigation and tree density on vegetative growth, oil yield and water use efficiency in young olive orchard under arid conditions in Mendoza. Argentina. Irrig Sci 33, 429-440.

Villalobos, F.J., Orgaz, F., Testi, L., Fereres, E., 2000. Measurement and modeling of evapotranspiration of olive (Olea europaea L.) orchards. Eur. J. Agron. 13, 155-163.

Villaobos, F.J., Testi, L., Hidalgo, J., Pastor, M., Orgaz, F., 2006. Modelling potential growth and yield of olive (Olea europaea L.) canopies. Eur. J. Agron. 24, 296-303.

Viola, F., Noto, L.V., Cannarozzo, M., La Loggia, G., Porporato, A., 2012. Olive yield as a function of soil moisture dynamics. Ecohydrology 5, 99-107.

Vossen, P., 2007. Olive oil: history, production, and characteristics of the world's classic oils. HortScience 42, 1093-1100.

Wang, Y.S., Jensen, C.R., Liu, F.L., 2017. Nutritional responses to soil drying and rewetting cycles under partial root-zone drying irrigation. Agric. Water Manag. 179, 254-259. 